THE INTERNATIONAL

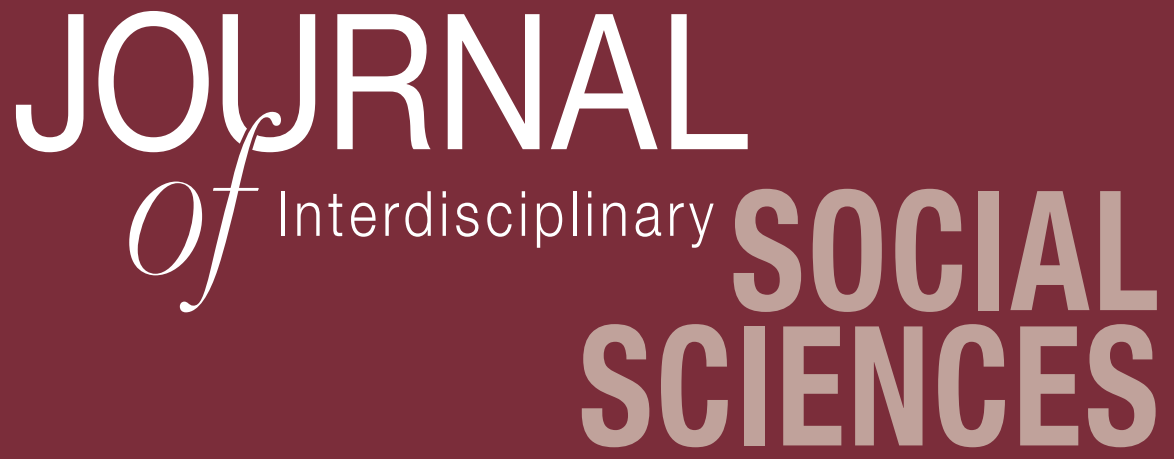

Volume 5, Number 6

Cooperative Research: An Example from the Wet Tropics of Queensland

Leanne Claire Cullen-Unsworth, James R A Butler, Rosemary Hill and Marilyn Wallace 
THE INTERNATIONAL JOURNAL OF INTERDISCIPLINARY SOCIAL SCIENCES http://www.SocialSciences-Journal.com

First published in 2010 in Champaign, Illinois, USA by Common Ground Publishing LLC www.CommonGroundPublishing.com.

(C) 2010 (individual papers), the author(s)

(C) 2010 (selection and editorial matter) Common Ground

Authors are responsible for the accuracy of citations, quotations, diagrams, tables and maps.

All rights reserved. Apart from fair use for the purposes of study, research, criticism or review as permitted under the Copyright Act (Australia), no part of this work may be reproduced without written permission from the publisher. For permissions and other inquiries, please contact

<cg-support@ commongroundpublishing.com>.

ISSN: 1833-1882

Publisher Site: http://www.SocialSciences-Journal.com

THE INTERNATIONAL JOURNAL OF INTERDISCIPLINARY SOCIAL SCIENCES is peer-reviewed, supported by rigorous processes of criterion-referenced article ranking and qualitative commentary, ensuring that only intellectual work of the greatest substance and highest significance is published.

Typeset in Common Ground Markup Language using CGCreator multichannel typesetting system

http://www.commongroundpublishing.com/software/ 


\title{
Cooperative Research: An Example from the Wet Tropics of Queensland
}

\author{
Leanne Claire Cullen-Unsworth, CSIRO Sustainable Ecosystems, \\ Queensland, Australia \\ James R A Butler, CSIRO Sustainable Ecosystems, Queensland, \\ Australia \\ Rosemary Hill, CSIRO Sustainable Ecosystems, Queensland, Australia \\ Marilyn Wallace, Bana Yarralji Bubu Incorporated, Helenvale, \\ Queensland, Australia
}

\begin{abstract}
In recent years there has been wider recognition of the important role that Indigenous knowledge can play in developing and implementing natural resource management (NRM) strategies. The biophysical surroundings of many Indigenous peoples are of symbolic significance to them, hence their perception and values of natural resources may be vastly different to those of scientists or managers. We discuss a research approach that explicitly embraces the co-production of knowledge to facilitate NRM in Australia. We demonstrate that if particular methodologies are used and specific criteria met, cooperative research can represent one pathway for the integration of Indigenous and scientific knowledge. We suggest an important step for genuine knowledge and systems integration is in research direction-setting. Our approach practices multi-directional learning and mutual benefit, promoting cross transfer of skills by the cooperative generation and documentation of information. Indigenous knowledge and associated systems are strengthened and the value of Indigenous knowledge and systems is recognised alongside accepted scientific knowledge and methods. Essential to the methodology used is the creation of partnerships based on trust between co-researchers and the generation of genuine action research outcomes.
\end{abstract}

Keywords: Cooperative Research, Indigenous Knowledge, Scientific Knowledge, Research Partnerships, Research Methods, Action Research, Adaptive Co-management, Knowledge Integration

\section{Introduction}

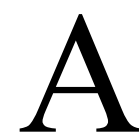

LL HUMANITY DEPENDS entirely on Earth's ecosystems and their associated services such as the provision of food, water and raw materials, their role in global biogeochemical cycling, climate regulation and storm protection (Dixon 1986, Barbier 1994, Costanza et al. 1997, Balmford et al. 2002, Wackernagel et al. 2002, Wilson 2002, MEA 2005, UNEP 2006). An ecosystem can be classified as a geographically specified system of organisms, environment and processes controlling its dynamics. Human beings are an integral component of the ecosystems in which they live and on which they depend (Wilson 2002, Puglise \& Kelty 2007), and healthy ecosystems can be characterised by their ability to sustain healthy human populations (Rapport et al. 1998).

Over the past 50 years humans have changed their ecosystems more swiftly and comprehensively than in any other comparable human period, largely to meet the growing demands

The International Journal of Interdisciplinary Social Sciences

Volume 5, Number 6, 2010, http://www.SocialSciences-Journal.com, ISSN 1833-1882

(c) Common Ground, Leanne Claire Cullen-Unsworth, James R A Butler, Rosemary Hill, Marilyn Wallace,

All Rights Reserved, Permissions: cg-support@commongroundpublishing.com 
of a growing population for food, water and raw materials (MEA 2005, UNEP 2006). Changes have resulted in significant gains in economic development and well-being for some people, but as a result others and the environment have suffered. Human beings are significantly changing the diversity of life on Earth and most of these changes represent a loss of biodiversity which is crucial to our continued well-being and survival (Norse 1993, MEA 2005).

In order to understand and potentially mitigate for the impacts of global environmental changes we must understand the impact of such changes on systems in which humans play an important role (Haber et al. 2006). Humans are a part of the ecosystem and we need to move beyond seeing human activities simply as disturbances to previously well functioning ecosystems (Haber et al. 2006, Schutkowski 2006). Accordingly, the management of ecosystems involves all people associated with those ecosystems (Borrini-Feyerabend et al. 2004). There is a need to understand links and dependencies between socioeconomic, sociocultural and ecological ecosystem dynamics within natural resource management (Bowen \& Riley 2003). Social, cultural, economic and political factors determine the success of environmental management initiatives far more than biological or physical factors (Fiske 1992, Kelleher \& Recchia 1998, Roberts 2000, Mascia 2003). Integration of ecological, cultural, social and economic disciplines and inclusion of the human element in all monitoring and management activities is the only reasonable way to move forward in the task of cultural, environmental, ecological and economic sustainability (Cullen 2007).

\section{Natural Resource Management}

There has been a growing movement to understand, protect and sustainably utilise ecosystems but there remain significant obstacles to successful conservation including: scientific or technical constraints such as limited knowledge of the value and vulnerability of ecosystems; inadequate dissemination of information; cultural issues such as the replacement of diverse human cultures adapted to sustainable living in diverse ecosystems by wasteful, consumer oriented world culture; economic issues; political constraints such as fragmented decision making and centralisation; and legal constraints (Norse 1993). Regardless of the obstacles, for conservation and sustainability to be achieved some form of management is essential. Management is a logical process about people (Worboys et al. 2005), various response options are available, for example regional and global agreements or local capacity development and stakeholder participation (UNEP 2006). Trade-offs must be made between the protection and use of natural resources and ways must be found to produce economic and cultural benefits from ecosystems whilst maintaining protection benefits (Dixon et al. 1993).

\section{Nature, Culture and Heritage}

There is no set definition of culture, however, the Australian Heritage Commission (2004) provides the following description: "the complex values, customs, beliefs and practices that constitute the way of life of a specific group of people". Cultural values can include aesthetic values; spiritual values; social values; historical values; symbolic values; and authenticity values (Australian Heritage Commission 2004).

Heritage includes our legacy from the past, how we live in the present, and what we pass on to future generations (UNESCO 2007). Worldwide there are examples of ecosystems that exist in their current state due to complex interactions between people and the environ- 
ment over time. Traditional patterns of land use have contributed to the maintenance of biodiversity and other natural values and shown the potential for sustainability over centuries. The resultant landscapes are living examples of cultural heritage, rich in natural and cultural values because of the presence of people. Protection of these landscapes requires an approach that recognises and integrates natural and cultural values, maintains traditional connections to the environment and engages people in the management of the landscape (Brown et al. 2005). Cultural diversity can sustain a variety of use practices and may have the potential to conserve natural resources (Posey 1999). However, although strong cultural values can be attached to natural resources by some communities, their use of these resources may not be sustainable (Cocks 2006).

The biophysical surroundings of many Indigenous people are of symbolic significance to them, hence their perception and values of natural resources are vastly different to those of (non-Indigenous) ecologists, conservationists or biologists (Posey 1999, Cocks 2006). Therefore there needs to be a more pragmatic approach to natural resource management that recognises the urgency and practicality of coordinating local communities, Indigenous and non-Indigenous, conservationists, and scientists (Orlove \& Briush 1996).

In some areas, conflicts can arise between the objectives of natural and cultural heritage conservation and compromises may be required to allow for the maintenance of ecological integrity in the long term whilst supporting and strengthening local culture. Resource management is required that includes the measurement and monitoring of cultural values and ecosystem health.

\section{Cultural Landscapes}

The Millennium Ecosystem Assessment (MEA 2005) identified that the importance of cultural values and services is rarely recognised within current landscape planning and management processes and that there would be benefit from a better understanding of the way communities manipulate ecosystems and the linking of this to cultural, spiritual and religious belief systems. The MEA further outlined that human culture is greatly influenced by ecosystems, and environmental changes can have a significant impact on cultural identity and social stability (MEA 2005). Greater attention needs to be given to the protection of landscapes as a complementary element within protected area systems, especially where biodiversity and cultural practices are linked (Brown et al. 2005).

Since 1992 Cultural Landscapes have been recognised by the World Heritage Convention and defined as "cultural properties that represent the combined works of nature and of man" designated in Article 1 of the World Heritage Convention (UNESCO 2005). The recognition of Cultural Landscapes reflects a trend towards a more holistic view of the environment (Pannell 2006) which reflects the Aboriginal view of Country as something not conceptually separate from humans (Anderson 1986). In this context, 'country' means place of origin, literally, culturally or spiritually. It can have the political meaning of 'nation', but refers to a clan or tribal area rather than a nation-state. 'Country' represents all the values, places, resources, stories, and cultural obligations associated with an area (Smyth 2007). Recognition of the importance of Cultural Landscapes prompts countries to source funds for their management and protection, and leads to increased respect for the landscape and its associated peoples (Plachter \& Rossler 1995). 


\section{Heritage in an Australian Context}

Aboriginal cultural heritage values can be defined as those ascribed to the whole landscape or places within due to their social, spiritual or historical associations (Horsfall 2002). Indigenous Australians maintain an intimate understanding of and close spiritual link to their environment (Aplin et al. 1999, Wet Tropics Aboriginal Plan Project Team 2005). Knowledge and management of Indigenous Australian cultural heritage is currently limited, however there is growing recognition of intangible cultural heritage and cultural landscapes, as well as the importance of heritage as part of people's identity and locality, which has been recognised in some states by the introduction of cultural landscapes as a heritage listing and mechanism for protection (Beeton et al. 2006). Knowledge of Indigenous heritage is especially limited outside of Indigenous communities particularly in relation to cultural values. While the Commonwealth of Australia (2004) encourages recognition of cultural heritage in Natural Resource Management (NRM) planning, there are no agreed measures for assessing or monitoring the state of cultural heritage (Beeton et al. 2006).

\section{The Use of Indicators}

A common challenge found in all conservation and development projects is to measure the success of management interventions (Margoluis \& Salafsky 1998). Indicators can be used to inform managers, policy makers and local communities of the effectiveness of management action or the impacts of inaction (Chabanet et al. 2005). At the national level indicators can be used to provide a holistic picture of ecological or cultural status; at the regional level, they can assist in the process of developing complementary strategies for the management of cross-boundary resources; and at the local level indicators can provide an operational tool in management as a bridge between objectives, management actions, and outcomes (FAO 1999). In general the purpose of indicators is to enhance communication, transparency, effectiveness and accountability (FAO 1999, Garcia et al. 1999, Segnestam 2002).

The establishment of indicator-driven programmes to monitor ecosystems has increasingly moved to stress socioeconomic impacts and drivers but socio-cultural impacts remain poorly understood with criteria and indicators poorly represented. Conservation of cultural and natural heritage and their associated values, tangible and intangible, can be monitored making use of indicators. However, to correctly reflect local cultural values and changes to cultural values, indicators must be developed with local communities.

In this paper we discuss the use of a cooperative research approach in the context of the development of appropriate Indigenous cultural indicators to monitor the cultural landscape of the Wet Tropics World Heritage Area (WTWHA). The indicators are potential cultural indicators that are linked to the biophysical environment of the WTWHA, capable of demonstrating why the WTWHA is important to Rainforest Aboriginal people. Although the WTWHA is not yet recognised by any official designation as a cultural landscape, it is currently under consideration for recognition as a cultural landscape on the National Heritage List and, if successful, it will be put forward for re-nomination as a cultural landscape on the World Heritage List. If re-listing is successful there will be a requirement to report on the cultural values for which the area is recognised. We used a cooperative research framework (Cullen at al 2008; Maclean and Cullen 2009) to develop a series of linked cultural and biophysical indicators to facilitate cooperative NRM across the WTWHA that reflects the 
values and beliefs of Traditional Owners and supports the goal of improving representations of Indigenous Culture in formal reporting frameworks.

\section{Research Direction-setting}

The overarching direction for this project was to develop appropriate cultural indicators at the community and regional scale for use in routine monitoring and management of the WTWHA. The need for this type of research was first identified in the Wet Tropics Regional Agreement (2005) and further specified through discussions between a council of Wet Tropics Aboriginal Elders and the CSIRO in 2006. Research was carried out in collaboration with representatives from a number of community case studies using a cooperative research framework. The aims of the work were identified collaboratively and were four-fold as follows: 1) To identify linked cultural and biophysical indicators for the WTWHA; 2) To develop a framework for indicator identification and a subsequent monitoring protocol; 3) To improve the benefits of scientific research for Traditional Owners and increase Traditional Owner capacity for World Heritage management and monitoring through cooperative research; and 4) To develop and apply methods of cooperative research.

\section{The Wet Tropics World Heritage Area (WTWHA)}

The WTWHA in Far North Queensland, Australia (figure 1) covers 894,420 ha and is one of the world's hotspots of rainforest biodiversity (RCSQ 1986, Goosem et al. 1999). The area is also rich in cultural heritage, with surrounding landscapes important nationally for agriculture and tourism (WTMA 2006). Like many globally important UNESCO sites (UNESCO 1972), the WTWHA is currently experiencing unprecedented rates of population growth and urbanisation (WTMA 2006), therefore efficient and effective management action is required to maintain the areas ecological, cultural and economic values. Direct environmental pressures on the WTWHA include: clearing and habitat fragmentation; altered drainage patterns and flow regimes; environmental pests; and undesirable habitat alteration or degradation (WTMA 2003). The Wet Tropics was inscribed on the World Heritage list in 1988 for its natural values, at which time it met all four criteria for a natural property (WTMA 2003). The Wet Tropics Management Authority (WTMA) was established in 1992 (ACIUCN 2000) and is the main body responsible for management of the WTWHA. Across the WTWHA ecological monitoring is being addressed. The commonwealth funded marine and tropical science research facility (MTSRF) supported the development of a monitoring programme for biodiversity identifying critical indicators and thresholds of concern. However, there remained a major scientific challenge to identify indicators for the cultural status of the Rainforest Aboriginal People who shaped the WTWHA Cultural Landscape.

\section{Cultural Heritage in the WTWHA}

One common element with heritage is the identification of assets considered worth preserving and sharing with present and future generations. At its most intimate level it can be a very personal concept. But it also helps define the groups to which we belong, including nations and ultimately humanity so it can also be very political (Aplin 2002). Scale is critical when defining heritage. Of local importance might not be of national or international importance 
and scale of consideration will affect the heritage protection afforded. Across Aboriginal Australia, natural and cultural heritage are inseparable.

The WTWHA is not recognised under the World Heritage Convention for its cultural values, nor do the natural values for which it is listed include the values attached to the natural environment by local Indigenous people (Horsfall 2002), however, there remains a widely held opinion that the Aboriginal cultural landscape is of world heritage significance (ACIUCN 2000). It is documented within World Heritage Periodic Reports (WTMA 2005) that the area between Cooktown and Cardwell contain the only recognised existing Australian Aboriginal rainforest culture, the oral history of whom is the oldest known for any surviving Indigenous people without a written language (Bottoms 2000). Aboriginal presence is though to date back at least 40,000 years (UNESCO World Heritage Centre 2003) and around eighty percent of the WTWHA is potentially claimable under the Native Title Act 1993 (UNESCO World Heritage Centre 2003).

Rainforest Aboriginal people would like to have the WTWHA recognised as a living Cultural Landscape, reflecting their view that natural and cultural values can not be separated (WTMA 2003). Cultural values include the ongoing traditions of Aboriginal people associated with the Wet Tropics and Aboriginal involvement in land management is essential to maintaining culture (WTMA 2003). Recognition of the Wet Tropics as a Cultural Landscape under the World Heritage Convention will require monitoring and management of Indigenous cultural values, therefore work is required to develop a robust and efficient routine monitoring programme reflecting Indigenous cultural values.

\section{Participation of Indigenous Communities in WTWHA Management}

Among actions taken by WTMA to improve involvement of Indigenous people in management of the WTWHA, the board approved a protocol to outline consultative arrangements between the Authority and Indigenous people (ACIUCN 2000). The Wet Tropics Regional Agreement (WTMA 2005) is an agreement to provide the basis for cooperative management of the WTWHA though policy development, strategic planning, park planning, permitting, operational management, monitoring and reporting and cultural heritage management. The Agreement recognises the significant contribution of Rainforest Aboriginal People to the management of the natural and cultural values of the WTWHA (WTMA 2005).

\section{Aboriginal Involvement in Management}

The Review of Aboriginal Involvement in the Management of the Wet Tropics World Heritage Area (Wet Tropics Review Steering Committee 1998) was based on a two year study into approaches to Aboriginal involvement in park management (ACIUCN 2000). One of the outcomes from the Review was that the existing state of management involvement of Aboriginal people in the WTWHA was limited and that management agencies were not living up to their obligations under legislation at that time. Consultation and cooperation with Aboriginal groups was particularly limited, specifically in relation to the protection of cultural values associated with the WTWHA. Part of the problem was identified as a lack of understanding, expertise and resources on the part of the management authority to carry out their obligations (Wet Tropics Review Steering Committee 1998). The review recommended the development of a more coordinated approach to the protection of cultural values that recog- 
nised the WTWHA as a series of dynamic Indigenous cultural landscapes and supported a proposal for a detailed assessment of the cultural values of the region as a precursor to the renomination of the WTWHA as a Cultural Landscape. The ACIUCN (2000) recommended that more satisfactory joint management arrangements be negotiated with rainforest Aboriginal people.

\section{Aboriginal Cultural and Natural Resource Management Plan}

The Aboriginal Cultural and Natural Resource Management Plan (Wet Tropics Aboriginal Plan Project Team 2005) was compiled by rainforest Traditional Owners with assistance from government, community groups, the Rainforest Cooperative Research Centre and Terrain NRM Ltd. The plan was developed because the Indigenous people of the Wet Tropics Region had not been involved in the development of a previous Natural Resource Management (NRM) plan for the WTWHA and the proposed level of engagement of Traditional Owners in the development of a new NRM plan was inadequate. Rainforest Aboriginal people made a collective decision to develop their own plan with the assistance of several key individuals (NHT 2004).

Key issues outlined in the Aboriginal plan included increased access to and use of country; use of Aboriginal knowledge of country; identification of cultural landscapes, places and materials; use of language; access to cultural and natural resources for hunting, gathering and cultural maintenance; and commercial use of resources (Wet Tropics Aboriginal Plan Project Team 2005). A cooperative and coordinated approach was outlined with strategies proposed to make the plan work (Wet Tropics Aboriginal Plan Project Team 2005). A key strategy identified was the development of and support for cooperative management arrangements.

\section{Cooperative Research in the Wet Tropics}

\section{Case Study Approach}

Our work used a case study approach across the WTWHA with three traditional owner groups as community partners. Community partners included Kuku Nyungkal in the North, Girramay in the centre and Warrgamay in the south WTWHA (see figure 1). Various selection criteria existed for the communities and included: Geographical spread across the WTWHA; the presence of willing research partners to work within the co-research framework; interest of participants in the wider community; and links with existing projects such as Cultural Heritage Mapping and Country Based Planning projects. Advice and direction was provided by the Aboriginal Rainforest Council (ARC) of elders (representing all 18 traditional owner groups from the WTWHA), Girringun Aboriginal Corporation, a Rainforest Aboriginal Advisory Committee (WTMA), an intellectual property sub-committee (ARC) and other key individuals. Links were made with other projects working in Indigenous communities at the request of traditional owners to try to achieve applied results and limit the impact and pressure on the communities from multiple projects. Active participation was part of the research process which included collaboration on research design to address local needs and priorities and prior review of results before publication or dissemination. In the initial stages of the project much time was invested in the cooperative development of research agreements 
and protocols for working together effectively. The project duration was three years from July 2007 to July 2010.

\section{Scale}

Scale was an important consideration throughout the project because the aim was to develop a series of regional-scale (whole of WTWHA) indicators. This proved difficult because at the community level there can be sensitive information that it is not appropriate to scale up. Additionally, cultural values are variable across the eighteen culturally diverse WTWHA traditional owner groups; although some overlap is apparent. Therefore, aims were revised with traditional owner co-researchers to identify community-scale indicators that will remain within the community and not be made publicly available, and identify a separate series of regional-scale indicators where there was appropriate overlap.

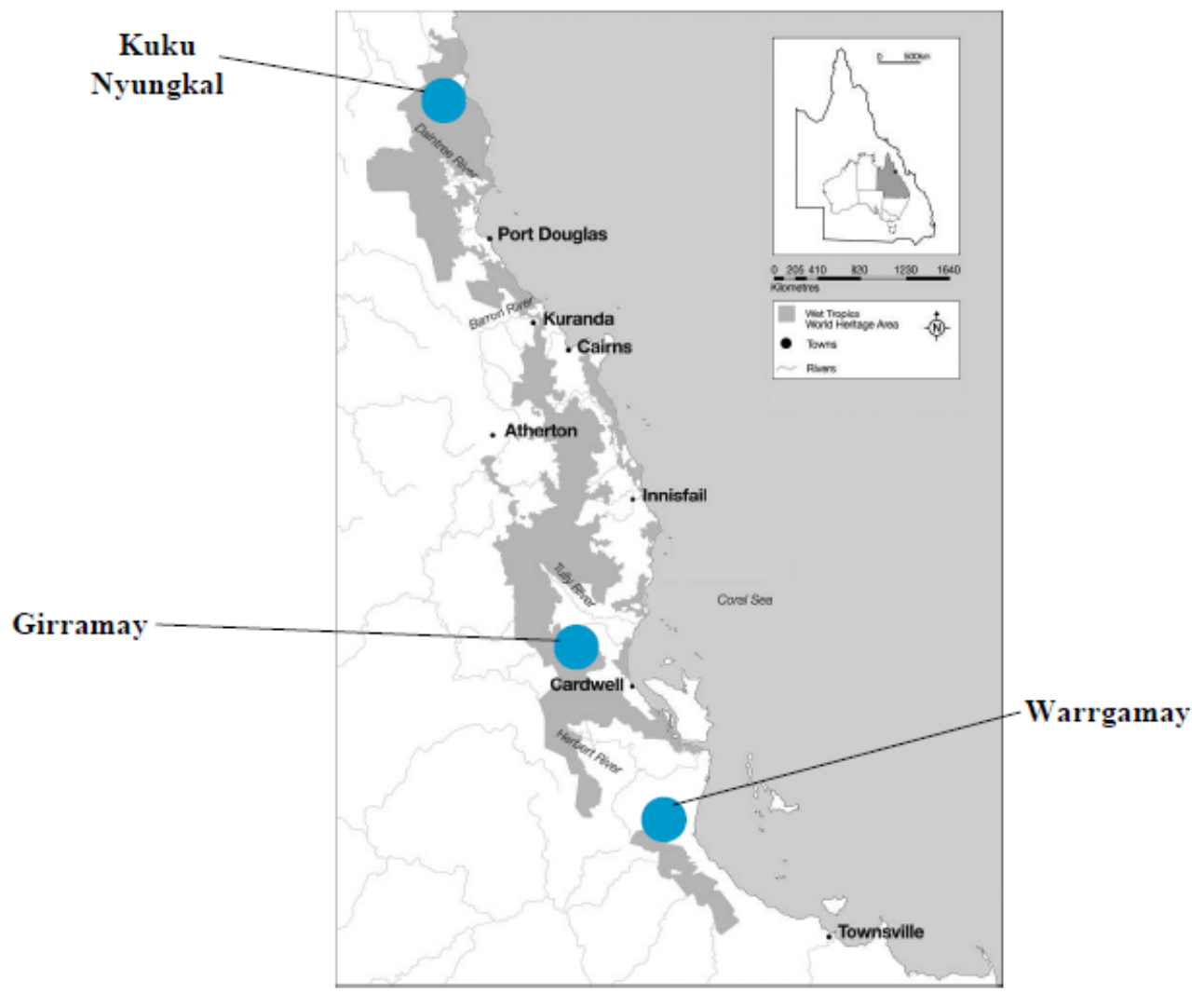

Figure 1: The Wet Tropics World Heritage Area in Far North Queensland, Australia, Showing Locations of Community Case Study Groups 


\section{Principles for Carrying out Cooperative Research with Indigenous Partners}

Successful co-research requires equity and acknowledgement of community partners and resource provision for their involvement as valued members of the research team. Additionally for successful co-research with Indigenous Australians, research must strengthen Indigenous knowledge, and not simply extract it. In the Wet Tropics region, work must also redefine the definition of research and science as described by Indigenous Australians in the Wet Tropics Regional Agreement (2005), into a more practical, responsive and applied way of working with Indigenous Australians. In our example traditional knowledge was valued alongside scientific knowledge (see Cullen et al 2008).

\section{Community-scale Indicators}

A series of separate meetings were held with community co-researchers from each of the three case study groups. Wherever logistically possible, meetings were held on the traditional country of each group. Discussions were focused around culture and how to monitor cultural values associated with the WTWHA. A report from a case study carried out in 2002 looking at cultural indicators for Girramay people Indicating Culture: development of cultural indicators for the management of the Wet Tropics World Heritage Area (Smyth, 2002) was also used as a framework for further discussion at the request of traditional owners to build on existing research. A list of potential indicators was developed for each community based on initial discussions then follow-up meetings held to further discuss the possibility of using identified community indicators at the regional scale. At this point a number of sensitive indicators were removed from each list and a new list, appropriate for discussion between all co-researchers (from each of the three community groups) was created.

\section{Regional-scale Indicator Identification}

A final intensive two-day workshop was held in May 2010 where all co-researches were present to discuss the development of a list of recommended regional-scale cultural indicators. The three existing potential regional-scale indicator lists were combined (with striking overlap apparent across the lists) and the appropriateness of each potential indicator, its cultural significance, and possible measurement strategies, were discussed in detail. This resulted in further removal of indicators from the list. The final list of recommended indicators will be verified and approved by traditional owners and included in a report to be presented for use across the WTWHA. Categories for the indicators were also discussed at the final workshop.

\section{Indicator Categories}

It was decided that all indicators fall under the greater umbrella of "Cultural Practices and Protocols" after which the indicators could be divided across six categories. The first five categories followed those outlined in the Indicating Culture report (Smyth 2002). The sixth category was simply called 'climate change' and was included because of the significance of the impacts of climate change on Indigenous peoples (Table 1); co-researchers were in 
agreement that this required a separate category representing a major and relatively new subject for consideration.

Table 1: Categories Selected for the Framing of Wet Tropics World Heritage Area Indigenous Cultural Indicators

\begin{tabular}{|c|c|c|}
\hline \multicolumn{3}{|c|}{ Cultural Practices and Protocols } \\
\hline & Categories & \\
\hline 1 & Recognition of rights and interests & \multirow{5}{*}{$\begin{array}{l}\text { Categories 1-5 from Rainforest CRC } \\
\text { Project } 1.5 \text { Final Report "Indicating Cul- } \\
\text { ture: development of cultural indicators } \\
\text { for the management of the Wet Tropics } \\
\text { World Heritage Area" (Smyth 2002) }\end{array}$} \\
\hline 2 & Participation in management & \\
\hline 3 & Socioeconomic benefits & \\
\hline 4 & Heritage and spiritual values & \\
\hline 5 & Understanding history & \\
\hline 6 & Climate change & $\begin{array}{l}\text { Additional category identified though } \\
\text { CSIRO and Traditional Owners of the } \\
\text { Wet Tropics co-research project "Identi- } \\
\text { fying linked cultural and biophysical in- } \\
\text { dicators for the WTWHA" }\end{array}$ \\
\hline
\end{tabular}

\section{Indicator Framework}

For Aboriginal Australians, nature and culture are inseparable and connections exist across all aspects of country, which implicitly includes culture. Therefore all categories and indicators identified are interlinked, connections can be made across all domains of country and any impact on country will be felt across the board. The relatively new science domain of ecosystem-based management reflects this Rainforest Aboriginal way of thinking, acknowledging that for any action on country there will be consequences felt throughout that country. This concept has been articulated well in the western way of thinking by the late Gerald Durrell who described the world as "as delicate and as complicated as a spider's web. If you touch one thread, you send shudders running through all the other threads." Therefore following the traditional Aboriginal world view, and delayed western-scientific realisation that everything is connected, our categories and indicators can be presented within a 'spider's web' framework. An example is given in figure 2. 


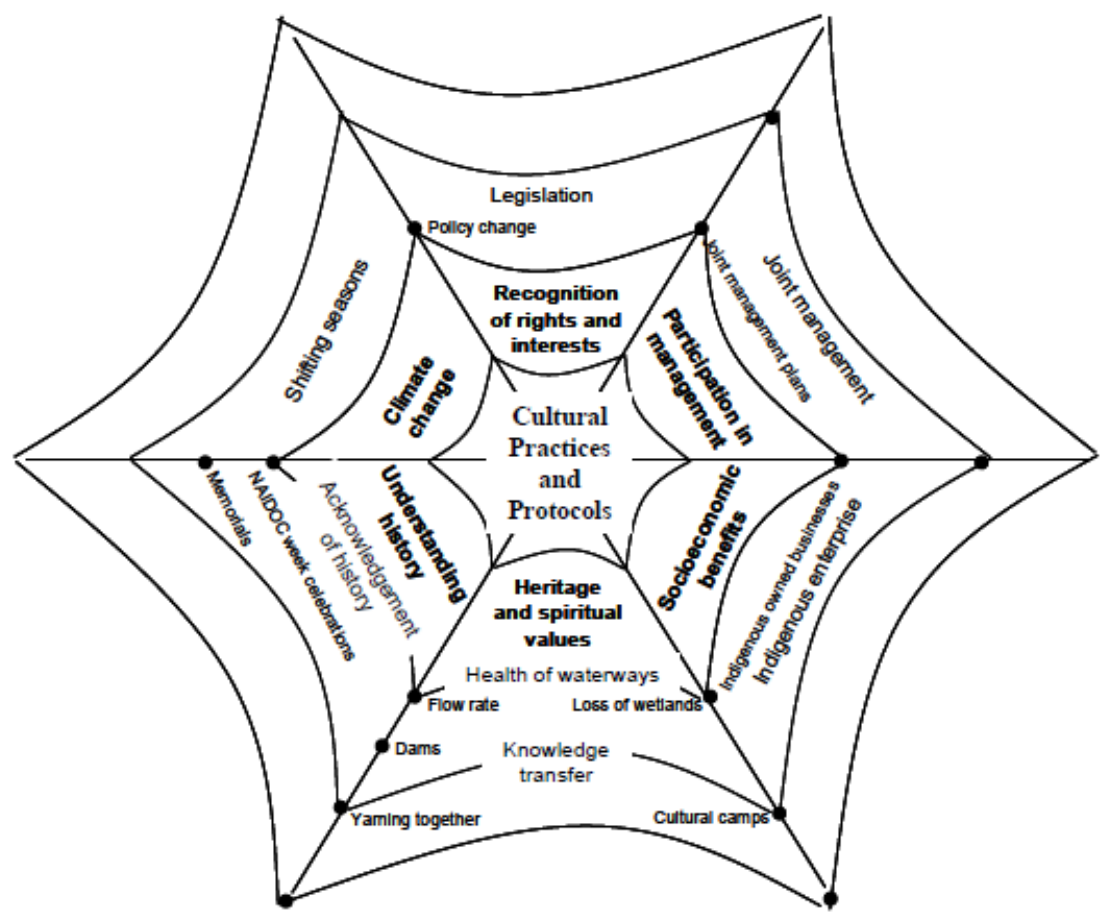

Figure 2: Example Spiders Web Framework for the Indigenous Cultural Indicators of the Wet Tropics World Heritage Area

\section{Use of Cultural Indicators}

In addition to routine regional monitoring and reporting Cultural Indicators can be included in joint management initiatives/proposals and used in Country Based Management Plans. The co-research approach supports Aboriginal participation in cultural heritage management, Cross-cultural development and understanding, Cross cultural conflict resolution, and integration into the decision making process.

\section{Outcomes from the Research Partnership}

The research partnership approach provides a platform for further Indigenous engagement in the management of the WTWHA and increases traditional owner capacity for monitoring and management. Other outcomes of the partnership include:

- Publications and reports co-authored by traditional owners acknowledge the credibility of traditional knowledge and traditional owner capacity for research and management.

- Links made with other projects develop community networks and further strengthen knowledge and capacity building. 
- Traditional science is seen as of equal importance as modern science resulting in Indigenous empowerment

- The indicators identified represent a 'bottom-up' approach and can be presented to agencies involved in WTWHA management and recommended for future use across planning and management

- Increased Indigenous engagement in heritage management and integration into decision making processes

- Support for self-monitoring and management of cultural heritage by traditional owners

\section{Emerging Issues}

It was felt by traditional owners of the WTWHA that in general there is a lack of cross-cultural understanding across the WTWHA and that more partnerships are needed to facilitate better understanding. Intergenerational transfer of traditional knowledge was also a concern with elders keen to engage youth in cultural activities and research on country. Scientific (and funding) timeframes were deemed inappropriate as they do not necessarily fit with local commitments and pressures, and hence more flexibility and ongoing support is required. Traditional owners made it clear that they would like to take responsibility for the compilation and reporting on indicators for their own country. Training in research design and implementation (action research) was requested along with the development of more research partnerships (rather than simply identification as end-users of research). Other emerging issues included research and project repetition with minimal feedback, and a need for improved accessibility to and clarity of information networks.

\section{Concluding Remarks}

Cooperative management of Protected Areas is a way to implement conservation and land management policies that integrate and protect Aboriginal interests (Lawrence 1996).

There is no universal plan for successful co-management of natural resources and a variety of case studies illustrate the complexities involved in the ongoing engagement of Indigenous people with the management of their specific country (Kerins et al. 2006). Therefore agreements must be site or community specific and negotiated as individual cases (Lawrence 1996), with the most appropriate and feasible form of management adopted. The co-management process must be adaptive and governance arrangements may change with altering capacities.

Indigenous people have legitimate interests in protected area management and biodiversity conservation and also have much to offer the broader community in the understanding of the Australian landscape and environment (Gilligan 2006). The engagement of Indigenous Australians through cooperative research is essential for cultural indicators to be meaningful; hence a best practice methodology is to use a co-research approach. The integration of value systems, thresholds of concern and indicators of ecosystem health or ecosystem integrity will then have the capacity to form the foundation of an engaging and cooperative management process.

Cooperative research for the co-production of knowledge is effective and can represent a pathway of integration for traditional and scientific knowledge if certain essential criteria are met. These criteria include: the development of partnerships based on trust; cooperative 
research direction-setting; action research outcomes; equity provision for co-researchers; and the strengthening and recognition of Indigenous knowledge alongside scientific knowledge.

Although we have developed regional-scale cultural indicators for the purpose of feeding in to regional scale monitoring and reporting requirements, co-management within the WTWHA must consider separate Aboriginal cultural identities. It's important to identify regional-scale indicators capable of reflecting regional-scale trends for inclusion in world heritage monitoring for example, but it's also important not to loose sight of the fact that the Wet Tropics region is highly biologically and culturally diverse and it is this 'biocultural' diversity that has arguably maintained the Wet Tropics Cultural Landscape for tens of thousands of years.

\section{References}

ACIUCN (2000) Wet Tropics of Queensland World Heritage Area: Condition, Management and Threats, Australian Committee for IUCN (ACIUCN), Sydney

Anderson C (1986) Queensland Aboriginal peoples today. In: Holmes JH (ed) Queensland: a geographical interpretation. Royal Geographic Society, Brisbane, p 296-320

Aplin G (2002) Australians and their environment: an introduction to environmental studies, Vol. Oxford University Press, Melbourne

Aplin G, Beggs P, Brierley G, Cleugh H, Curson PM, P, Pitman A, Rich D (1999) Global environmental crises: an Australian perspective, Vol. Oxford University Press, Melbourne

Australian Heritage Commission (2004) Heritage Economics: challenges for heritage conservation and sustainable development in the 21st century Heritage Economics: challenges for heritage conservation and sustainable development in the 21st century. Australian Heritage Commission (AHC), Auatralian National University, Canberra, p 247

Balmford A, Bruner A, Cooper P, Costanza R, Farber S, Green RE, Jenkins M, Jefferiss P, Jassamy V, Madden J, Myers N, Naeem S, Paavola J, Rayment M, Rosendo S, Roughgarden J, Trumper K, Turner KR (2002) Economic reasons for conserving wild nature. Science 297:950954

Barbier EB (1994) Valuing environmental functions: tropical wetlands. Land Economics 70:155-173

Beeton R, Buckley KI, Jones GJ, Morgan D, Reichelt RE, Trewin D (2006) Australia State of the Environment 2006, Independent report to the Australian Government Minister for the Environment and Heritage (2006 Australian State of the Environment Committee). http://www.environment.gov.au/soe/themes/heritage/index.html

Borrini-Feyerabend G, Kothari A, Oviedo G (2004) Indigenous and Local Communities and Protected Areas: Towards Equity and Enhanced Conservation, IUCN, Gland, Switzerland and Cambridge, UK

Bottoms T (2000) Bama Country - Aboriginal Homelands. In: McDonald G, Lane M (eds) Securing the Wet Tropics. The Federation Press, Sydney, p 32-47

Bowen RE, Riley C (2003) Socio-economic indicators and integrated coastal management. Ocean and Coastal Management 46:299-312

Brown J, Mitchell N, Beresford M (eds) (2005) The protected landscape approach: linking nature, culture and community, Vol. IUCN, Gland, Switzerland and Cambridge, UK

Chabanet P, Adjeroud M, Andrefouet S, Bozec Y-M, Ferraris J, Garcia-Charton JA, Schrimm M (2005) Human-induced physical disturbances and their indicators on coral reef habitats: a multiscale approach. Aquatic Living Resources 18:215-230

Cocks M (2006) Biocultural diversity: moving beyond the realm of 'indigenous' and 'local people'. Human Ecology 34:185-200 
Costanza R, d'Arge R, de Groot R, Farber S, Grasso M, Hannon B, Limburg K, Naeem S, O'Neil RV, Paruelo J, Raskin RG, Sutton P, van den Belt M (1997) The value of the world's ecosystem services and natural capital. Nature 387:253-260

Cullen LC, Butler JRA, Hill R, Margules C (2008). Framework for the identification of linked cultural and biophysical indicators for the wet tropics world heritage area. The International Journal of Environmental, Cultural, Economic and Social Sustainability 4: 37-46.

Cullen LC (2007) Natural Resource Dependence, Resource Use Patterns and Development of Economic Performance Criteria within a Small Island Community, Kaledupa, Indonesia. University of Essex

Dixon JA (1986) The role of economics in valuing environmental effects of development projects. In: Dixon JA, Hufschmidt MM (eds) Economic valuation techniques for the environment A case study workbook. John Hopkins University Press, p 3-10

Dixon JA, Fallon Scura L, van't Hof T (1993) Meeting ecological and economic goals: Marine Parks in the Caribbean. Ambio 22:117-125

FAO (1999) Indicators for sustainable development of marine capture fisheries. Report No. 8, FAO Fishery Resources Division

Fiske SJ (1992) Sociocultural aspects of establishing marine protected areas. Ocean and Coastal Management 18:25-46

Garcia SM, Staples DJ, Chesson J (1999) The FAO guidelines for the development and use of indicators for sustainable development of marine capture fisheries and an Australian example of their application. Report No. CM 1999/P:05, International Council for the Exploration of the Sea, Bureau of Rural Sciences

Gilligan B (2006) The Indigenous Protected Areas Programme: 2006 Evaluation

Goosem S, Morgan G, Kemp JE (1999) Wet Tropics. In: Sattler P, Williams R (eds) The Conservation Status of Queensland's Bioregional Ecosystems. Environmental Protection Agency, Brisbane, p 73

Haber H, Winiwarter V, Andersson K, Ayres RU, Boone C, Castillo A, Cunfer G, Fischer-Kowalski M, Freudenburg WR, Furman E, Kaufmann R, Krausmann F, Langthaler E, Lotze-Campen H, Mirtl M, Redman CL, Reenberg A, Wardell A, Warr B, Zechmeister H (2006) From LTER to LTSER: conceptualizing the socioeconomic dimension of long-term socioecological research Ecology and Society, p 13-46

Horsfall N (2002) Cultural or Natural? The Applicability of World Heritage Criteria to Aboriginal Cultural Values in the Wet Tropics. Tempus 7:151-155

Kelleher G, Recchia C (1998) Lessons from marine protected areas around the world. Parks 8:1-4

Kerins S, Lennon J M L (2006) Indigenous involvement in environmental and heritage management. In: Brown R, Creaser P (eds) Case studies prepared for the 2006 Australian State of the Environment Committee. Department of the Environment and Heritage, Canberra, http://www.deh.gov.au/soe/2006/integrative/indigenous/index.html

Lawrence, D (1996) Managing Parks/Managing 'Country': Joint Management of Aboriginal Owned Protected Areas in Australia, Parliament of Australia, Parliamentary Library: Research Paper 2

Maclean K, Cullen L C (2009) Research methodologies for the co-production of knowledge for environmental management in Australia. New Zealand Journal of Zoology: Forum on CrossCultural Approaches to Environmental Research and Management, 36(4): 205-208.

Margoluis R, Salafsky N (1998) Measures of Success: Designing, Managing, and Monitoring Conservation and Development Projects, Vol. Island Press, Washington, D. C.

Mascia MB (2003) The human dimension of coral reef marine protected areas: Recent social science research and its policy implications. Conservation Biology 17:630-632

MEA (2005) Cultural and Amenity Services, Millennium Ecosystem Assessment Series: Volume 1, Island Press, Washington, Covelo, London 
MEA (2005) Millennium Ecosystem Assessment. Ecosystems and Human Well-being: Synthesis, Island Press, Washington, DC

NHT (2004) Developing an Aboriginal Plan for the Wet Tropics NRM Region in North Queensland, Prepared by Smyth and bahrdt Consultants for the Natural Heritage Trust

Norse EA (1993) Global marine biological diversity: A Strategy for Building Conservation into Decision Making, Vol. Island Press

Orlove BS, Briush SB (1996) Anthropology and the conservation of biodiversity. Annual Reviews in Anthropology 25:329-352

Pannell S (2006) Reconciling Nature and Culture in a Global Context? Lessons from the World Heritage List, Cooperative Research Centre for Tropical Rainforest Ecology and Management. Rainforest CRC, Cairns, Australia

Plachter H, Rossler M (1995) Cultural Landscapes: reconnecting culture and nature. In: von Droste B, Plachter H, Rossler M (eds) Cultural landscapes of universal value. Gustav Fischer Verlag Jena in cooperation with UNESCO, Stuttgart, $\mathrm{p}$ 15-20

Posey DA (1999) Cultural and spiritual values of biodiversity. A complementary contribution to the global biodiversity assessment. In: Posey DA (ed) Cultural and spiritual values of biodiversity. UNEP and Intermediate Technology Publications, London, UK, p 1-19

Puglise KA, Kelty R (eds) (2007) NOAA Coral Reef Ecosystem Research Plan for Fiscal Years 2007 to 2011, Vol. Silver Spring, MD: NOAA Coral Reef Conservation Program. NOAA Technical Memorandum CRCP 1

Rapport D, Gaudet C, Constanza R, Epstein PR, Levins R (1998) Defining ecosystem health. In: Rapport D, Gaudet C, Constanza R, Epstein PR, Levins R (eds) Ecosystem Health: Principles and Practice. Blackwell Science Inc, Oxford, UK, p 18-33

RCSQ (1986) Tropical Rainforests of North Queensland: their conservation significance, Vol. Report to the Australian Heritage Commission by the Rainforest Conservation Society of Queensland (RCSQ). Australian Government Publishing Service, Canberra

Roberts CM (2000) Selecting marine reserve locations: optimality versus opportunism. Bulletin of Marine Science 66:581-592

Schutkowski H (2006) Human Ecology: biocultural adaptations in human communities, Vol 182. Springer, Berlin Heidelberg, Germany

Segnestam L (2002) Indicators of Environment and Sustainable Development: theories and practical experience. Report No. Paper No. 89, The World Bank Environment Department, Washington, D. C.

Smyth D (2007) Understanding Country: The Importance of Land and Sea in Aboriginal and Torres Strait Islander Societies, Key Issues Paper, Council for Aboriginal Reconciliation, Australian Institute of Aboriginal and Torres Strait Islander Societies.

UNEP (2006) Marine and coastal ecosystems and human well-being: A synthesis report based on the findings of the Millennium Ecosystem Assessment, UNEP

UNEP (2006) Report of the eighth meeting of the parties to the Convention on Biological Diversity. In: UNEP/CBD/COP/8/31 (ed) Convention on Biological Diversity, Curitiba, Brazil, 20-31 March 2006

UNESCO (1972) Convention Concerning the Protection of the World Cultural and Natural Heritage, United Nations Educational, Scientific and Cultural Organisation, Paris

UNESCO (2005) Operational Guidelines for the Implementation of the World Heritage Convention, United Nations Educational, Scientific and Cultural Organisation, Paris

UNESCO (2007) World Heritage. http://whc.unesco.org/en/about/

Wackernagel M, Schulz NB, Deumling D, Callejas Linares A, Jenkins M, Kapos V, Monfreda C, Loh J, Myers N, Norgaard R, Randers J (2002) Tracking the ecological overshoot of the human economy. Proceedings of the National Academy of Sciences of the United States of America (PNAS) 99:9266-9271 
Wet Tropics Aboriginal Plan Project Team (2005) The Wet Tropics Aboriginal Cultural and Natural Resource Management Plan: Caring for Country and Culture, Rainforest CRC and FNQ NRM Ltd, Cairns

Wet Tropics Review Steering Committee (1998) The review of Aboriginal involvement in the management of the Wet Tropics World Heritage Area, Prepared for the Wet Tropics Board of Management by the Review Steering Committee

Wilson EO (2002) The future of life, Vol. Little, Brown and Alfred A. Knopf, Inc, London, UK

Worboys GL, Lockwood M, De Lacey T (2005) Protected area management: principles and practice, Vol. Oxford University Press

WTMA (2003) Periodic Report on the Application of the World Heritage Convention, Wet Tropics Management Authority (WTMA) in conjunction with Environment Australia

WTMA (2005) Wet Tropics of Queensland World Heritage Area Regional Agreement, Wet Tropics Management Authority (WTMA)

WTMA (2006) Annual Report and State of the Wet Tropics Report 2005 - 2006, Wet Tropics Management Authority (WTMA)

\section{About the Authors}

Dr. Leanne Claire Cullen-Unsworth

Leanne worked as an Environmental Scientist with CSIRO developing linked socio-cultural and biophysical indicators for the Queensland Wet Tropics World Heritage Area. Her PhD research looked at the direct economic value of natural marine resources to local dependents; resource use patterns; alternative livelihoods; and developed a series of economic performance criteria to monitor the local economic impacts of management/non-management within a small island community in a marine national park in Indonesia. Leanne has an MSc in Marine Environmental Protection (2000-2001) from the University of Wales, Bangor and BSc (honours) in Marine Biology from the University of Newcastle upon Tyne (1997-2000).

Dr. James $R$ A Butler

CSIRO Sustainable Ecosystems, Australia

Dr. Rosemary Hill

CSIRO Sustainable Ecosystems, Australia

Marilyn Wallace

Bana Yarralji Bubu Incorporated, Helenvale, Australia 


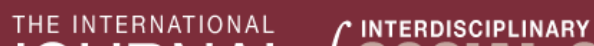 JOURNAL Of SOGHAL SGIENGES}

\section{EDITORS}

Mary Kalantzis, University of Illinois, Urbana-Champaign, USA.

Bill Cope, University of Illinois, Urbana-Champaign, USA.

\section{EDITORIAL ADVISORY BOARD}

Patrick Baert, Cambridge University, Cambridge, UK.

Norma Burgess, Syracuse University, Syracuse, USA.

Bill Cope, University of Illinois, Urbana-Champaign, USA.

Peter Harvey, University of Adelaide, Adelaide, Australia.

Vangelis Intzidis, University of the Aegean, Rhodes, Greece.

Paul James, RMIT University, Melbourne, Australia.

Mary Kalantzis, University of Illinois, Urbana-Champaign, USA.

Gerassimos Kouzelis, University of Athens, Athens, Greece.

Massimo Leone, University of Turin, Turin, Italy.

Alexandros-Andreas Kyrtsis, University of Athens, Athens, Greece.

José Luis Ortega Martín, Universidad de Granada, Granada, Spain.

Bertha Ochieng, University of Bradford, Bradford, UK.

Francisco Fernandez Palomares, Universidad de Granada, Granada, Spain.

Miguel A. Pereyra, Universidad de Granada, Granada, Spain.

Constantine D. Skordoulis, University of Athens, Athens, Greece.

Chad Turnbull, ESADE Business School, Barcelona, Spain.

Chryssi Vitsilakis-Soroniatis, University of the Aegean, Rhodes, Greece.

Please visit the Journal website at http://www.SocialSciences-Journal.com for further information about the Journal or to subscribe. 


\section{THE UNIVERSITY PRESS JOURNALS}

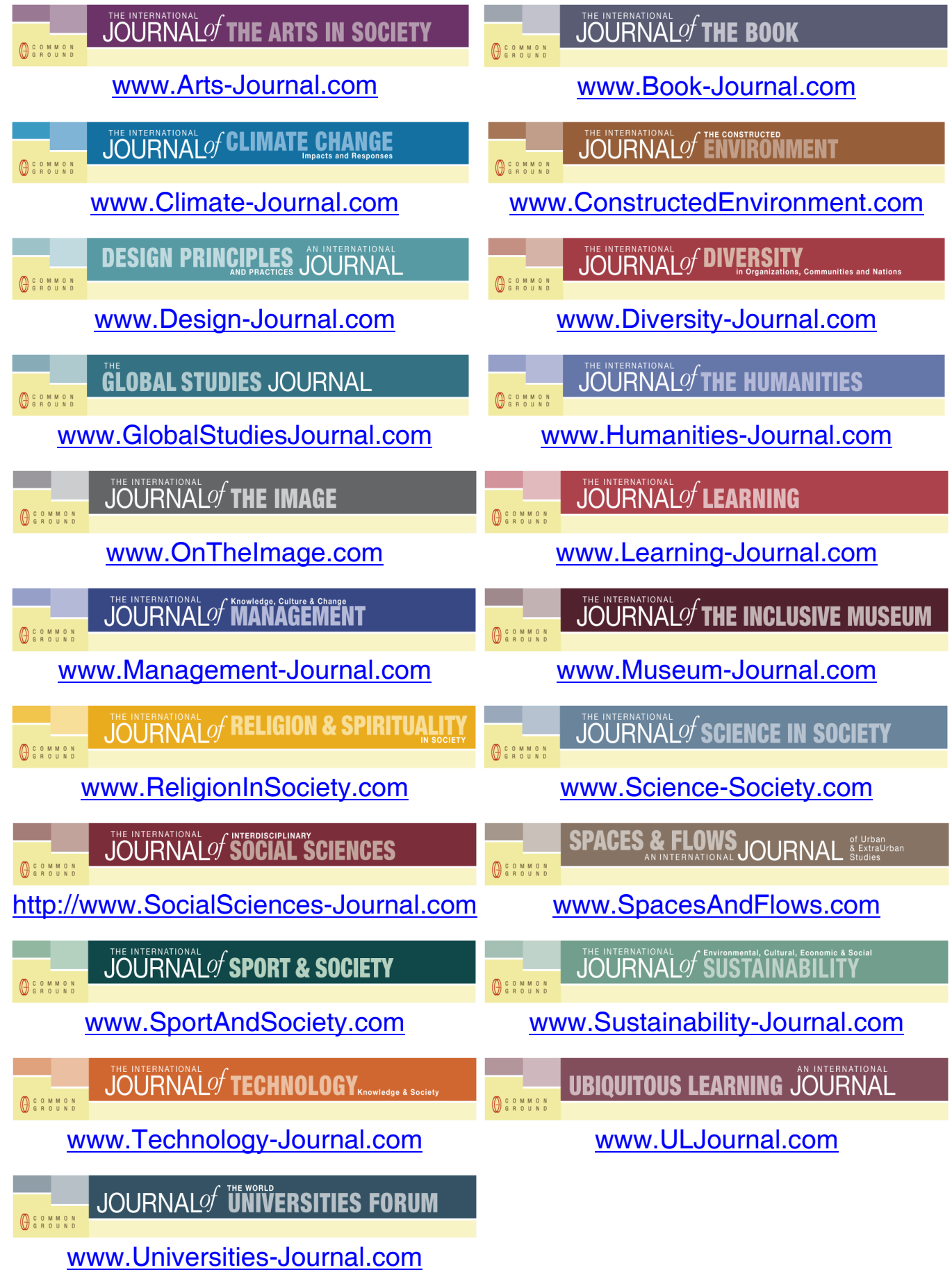

FOR SUBSCRIPTION INFORMATION, PLEASE CONTACT subscriptions@commongroundpublishing.com 